\title{
Leveraging Industry Visualization Tools for Biodiversity Science
}

\author{
Jocelyn Pender $\ddagger$ \\ ‡ Agriculture and Agri-Food Canada, Ottawa, Canada
}

Corresponding author: Jocelyn Pender (pender.jocelyn@gmail.com)

Received: 15 Apr 2018 | Published: 22 May 2018

Citation: Pender J (2018) Leveraging Industry Visualization Tools for Biodiversity Science. Biodiversity

Information Science and Standards 2: e25842. https://doi.org/10.3897/biss.2.25842

\begin{abstract}
Widespread technology usage has resulted in a deluge of data that is not limited to scientific domains. For example, technology companies accumulate vast amounts of data on their users to support their applications and platforms. The participation of many domains in big data collection, data analysis and visualization, and the need for fast data exploration has provided a stellar market opportunity for high quality data visualization software to emerge. In this talk, leading industry visualization software (Tableau) will be used to explore a biodiversity dataset (Carex spp. distribution and morphology). The advantages and disadvantages of using Tableau for scientific exploration will be discussed, as well as how to integrate data visualization tools early into the data pipeline. Lastly, the potential for developing a data visualization "stack" (i.e., a combination of software products and programming languages) using available tools will be discussed, as well as what the future might look like for scientists looking to capitalize on the growth of industry tools.
\end{abstract}




\section{Keywords}

data visualization, Tableau, Carex spp., industry data tools

\section{Presenting author}

Jocelyn Pender 